Correction

\title{
Correction: Banh, J. “I Have an Accent in Every Language I Speak!": Shadow History of One Chinese Family's Multigenerational Transnational Migrations. Genealogy 2019, 3, 36
}

\section{Jenny Banh}

Department of Anthropology and Asian American Studies, California State University, Fresno, CA 93740, USA; jenbanh@mail.fresnostate.edu

Received: 21 September 2020; Accepted: 22 September 2020; Published: 24 September 2020

The author wishes to make the following corrections to this paper (Banh 2019):

(1) Remove the following sentence from the article on page 5 :

Monica Trieu says her family is "publicly Vietnamese" but privately Chinese meaning they tell people they are Vietnamese but at home they identify as Chinese.

(Trieu 2009)

(2) Remove Reference from the following sentence on Section 5 in page 7:

They also have varying identities as some identify as fully Vietnamese to partly Chinese-Vietnamese to fully Chinese according to the situation (Trieu 2009).

(3) Delete the following reference:

(Trieu 2009) Trieu, Monica. 2009. Identity Construction among Chinese-Vietnamese Americans: Being, Becoming, and Belonging. El Paso: LFB Scholarly Publishing.

The author would like to apologize for any inconvenience caused to the readers by these changes.

\section{References}

Banh, Jenny. 2019. "I Have an Accent in Every Language I Speak!": Shadow History of One Chinese Family's Multigenerational Transnational Migrations. Genealogy 3: 36. [CrossRef]

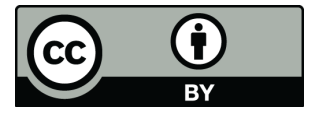

